ORIGINAL ARTICLE

\title{
Endotelium in Turner syndrome with capillaroscopy
}

\section{Endotélio na síndrome de Turner com capilaroscopia}

\author{
Simone Cristina da Silva Coelho', Marília Martins Guimarães², Terezinha Jesus Fernandes³
}

\begin{abstract}
Objective: The aim of this study was to assess the endothelium function in patients with Turner syndrome using videocapillaroscopy and to compare the results with healthy control.

Methods: Subjects and controls were studied in a temperature-controlled room, 20 days after no nailfold manipulations. The capillaries were visualized by a microscope connected to a television and a computer. The test of post-occlusive reactive hyperemia was performed using a sphygmomanometer attached to the fourth left finger, $20 \mathrm{mmHg}$ above maximum arterial pressure during 1 minute, and the following patterns were studied: area of transverse segment, maximal post-ischemia area and time to reach maximal post-ischemia area.

Results: The value of measure of transverse segment projected area, the maximal postischemia area of hand nailfold capillary loops using computerized videophotometry and the time to reach maximal post ischemia area were studied in 40 patients with Turner syndrome and 26 healthy women controls of comparable age $(20 \pm 7.5$ versus $18 \pm 8.1$ years old; $p=0.57)$. There were differences between transverse segment area $(706.8 \pm 139.1$ versus $548.8 \pm 117.2$; $p=0.001)$. Maximal post-ischemia area $(891.3 \pm 226.1$ versus $643.5 \pm 134.3 ; p=0.001)$ and the time to reach it $(10.8 \pm 4.3$ versus $5.5 \pm 2.5 ; p=0.001)$ were different between patients and controls.

Conclusions: Changes of capillary response to ischemia could be observed in patients with Turner syndrome using videocapillaroscopy when they were compared to a healthy control group.
\end{abstract}

Keywords: Turner syndrome; microscopic angioscopy; endothelium.

\section{Resumo}

Objetivos: O objetivo deste estudo foi avaliar a função endotelial de pacientes com síndrome de Turner, utilizando a videocapilaroscopia e comparar os resultados com grupo controle saudável.

Métodos: Pacientes e controles foram estudados em sala com temperatura controlada, após 20 dias, sem a manipulação das cutículas. Os capilares foram visualizados por microscópio conectado a televisão e computador. O teste de hiperemia reativa pós-oclusiva foi realizado utilizando-se esfigmomanômetro fixado no quarto quirodáctilo da mão esquerda, $20 \mathrm{mmHg}$ acima da pressão arterial máxima durante 1 minuto, e os seguintes parâmetros foram estudados: área do segmento transverso, área máxima pós-hiperemia e tempo para alcançar a área máxima pós-hiperemia.

Resultados: $\mathrm{O}$ valor da área do segmento transverso, área máxima pós-hiperemia dos capilares da região da mão usando-se a videocapilaroscopia computadorizada e o tempo para alcançar a área pós-hiperemia foram estudadas em 40 pacientes com síndrome de Turner e 26 controles do sexo feminino pareados para idade ( $20 \pm 7,5$ versus $18 \pm 8,1$ anos; $p=0,57)$. Houve diferenças nos grupos quanto à área do segmento transverso $(706,8 \pm 139,1$ versus 548,8 $\pm 117,2 ; p=0,001)$. A área máxima pós-hiperemia $(891,3 \pm 226,1$ versus $643,5 \pm 134,3 ; p=0,001)$ e o tempo para alcançá-la (10,8 $\pm 4,3$ versus $5,5 \pm 2,5 ; p=0,001)$ foram significativamente diferentes entre pacientes e controles.

Conclusão: Houve alterações na resposta do capilar à isquemia em pacientes com síndrome de Turner utilizando-se videocapilaroscopia quando comparados ao grupo controle saudável.

Palavras-chave: Síndrome de Turner; angioscopia microscópica; endotélio.

Study carried out at Universidade Federal do Rio de Janeiro (UFRJ), Rio de Janeiro (RJ), Brazil.

'PhD Student of Endocrinology Service of the Universidade Federal do Rio de Janeiro (UFRJ), Rio de Janeiro (RJ), Brazil.

${ }^{2}$ Adjunct Professor of Endocrinology Service of the UFRJ, Rio de Janeiro (RJ), Brazil.

${ }^{3}$ Adjunct Professor of Angiology of the UFRJ, Rio de Janeiro (RJ), Brazil.

No conflicts of interest declared concerning the publication of this article.

Received on: 04.12.10. Accepted on: 12.04.11

J Vasc Bras. 2011;10(2):119-123. 


\section{Introduction}

Turner syndrome (TS) is characterized by total or partial loss of a sex chromosome ${ }^{1}$.

It occurs in approximately $1 / 2,500$ live births with feminine phenotype ${ }^{2}$, which represents more than $1 / 500,000$ women worldwide ${ }^{2}$. The two most common features, which affect over $90 \%$ of recognized patients, are short stature and premature ovarian failure. There are also a series of phenotypical alterations that occur with variable frequency ${ }^{3}$. Morbidity is clearly increased and these patients demonstrate a greater prevalence of arterial hypertension ${ }^{4}$, central obesity, reduction of insulin sensitivity ${ }^{5}$, impaired glucose tolerance ${ }^{6}$ and diabetes mellitus ${ }^{7,8}$.

Cardiovascular complications in Turner syndrome are the most common cause of early mortality, with a life expectancy that may be reduced by more than ten years?

The dilatations of ascending aorta are often described and may be an isolated factor, suggesting a vasculopathy specific to the syndrome, probably related to extracardiac factors such as estrogen deficiency, diabetes, dyslipidemia and overweight ${ }^{10}$.

Endothelium disturbance is present in groups with increased risk for diabetes and insulin resistance ${ }^{11}$.

Human microcirculation can be studied in vivo, using different methods, such as plethysmography and capillaroscopy ${ }^{12,13}$.

The aim of this study was to assess the endothelium function in these patients by means of videocapillaroscopy and to compare it to healthy control.

\section{Methods}

A cross-sectional study was designed with no diabetic TS patients, with diagnosis confirmed by karyotype and
26 healthy control in 2008. Effective use of vascular drugs, hepatopathy, renal failure, vascular disorders, diabetes and hand lesions were exclusion criteria. This study was approved by Ethical Comitte of the institution where it was performed, under the number 085/06.

Videocapillaroscopy was performed in a temperature controlled room $\left(24-26^{\circ} \mathrm{C}\right)$, in the morning following a night fasting, 20 days after no nailfold manipulations. The patients and control subjects were comfortably seated in a chair with observed hand at heart level with forearm and hand bent at the elbow. All subjects had their arm blood pressure measures in this position using auscultatory method. Capillaries were visualized by microscope Wild Leitz GLS100 connected to a television monitor and computer.

Post occlusive reactive hyperemia was performed using a sphygmomanometer attached to the fourth left hand finger, $20 \mathrm{mmHg}$ above maximum arterial pressure during $1 \mathrm{minu}-$ te. Images were captured by a computer through Pinnacle 5.0 software, each 2 seconds, during 1 minute after releasing pressure. Measures were determined through Studio2.0 software by at least two investigators blind to clinical data an in two different moments by each investigator to establish the concordance $(\mathrm{k}>0.7$ in both). A perpendicular line tangent to internal limit of a capillary loop transverse segment defined the transverse segment area (TSA) to be measured (Figure 1). Zero time point after ischemia was considered just after releasing finger pressure. Maximum post ischemia area (MAI) and time to get the maximum post ischemia area (MAIt) was determined in TS and controls.

\section{Statistical analysis}

Data were expressed as mean \pm standard deviation (SD). The statistical analysis was obtained with Student $\mathrm{t}$-test and
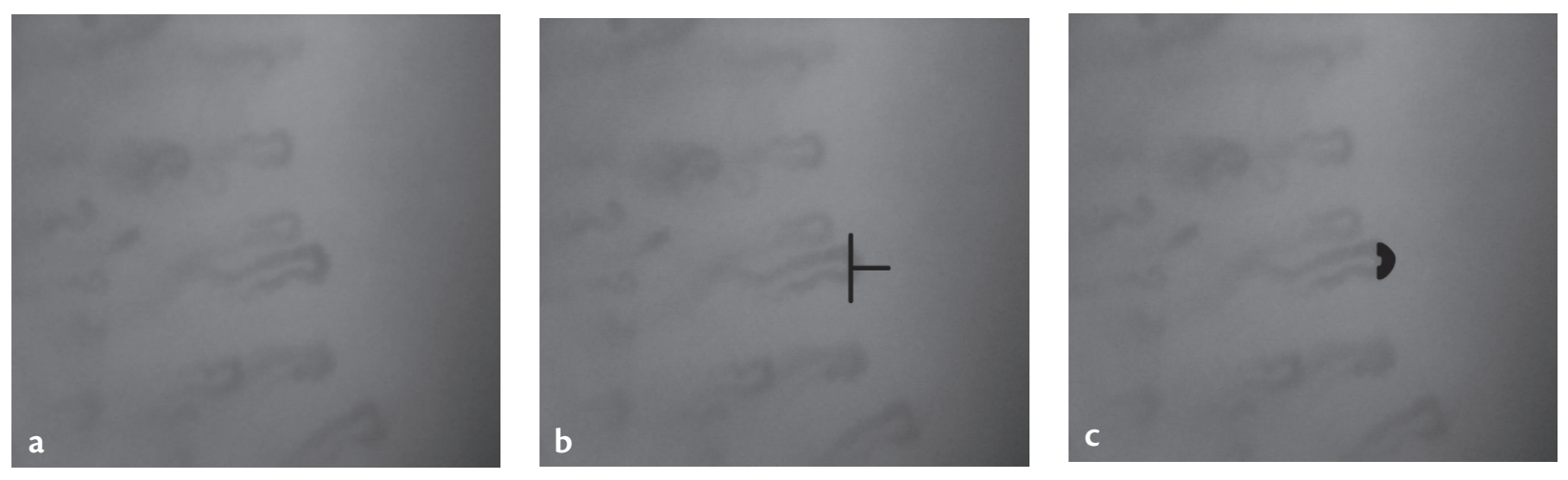

Figure 1 - Image with: a) capillary, b) transverse segment area (TSA) and c) maximum post-ischemia area. 
Mann-Whitney test. A value of $\mathrm{p}<0.05$ was considered statistically significant.

\section{Results}

Forty patients with TS and 26 health controls were studied, aged between 8-38 years. The subjects were classified in Groups 1 (TS) and 2 (control). Both groups had comparable ages $(20 \pm 7.5$ versus $18 \pm 8.1$ years old; $\mathrm{p}=0.57)$. The karyotype of 23 (58\%) patients was 45,X and of 17 (42\%) ones were mosaic. Nine (23\%) patients with TS were prepubertal and $30(77 \%)$ were postpuberal, meanwhile 5 (19\%) controls were prepubertal and 21 (81\%) were postpuberal with no statistical differences $(\mathrm{p}=0,79)$. Spontaneus puberty occurred in $5(12 \%)$ patients with TS and all continued to present regular menses. Both groups had comparable body mass index $(\mathrm{p}=0.45)$. The diabetes familial history was similar between groups $(\mathrm{p}=0.45)$.

Table 1 shows that there were differences in measures between TS and controls before the post occlusive reactive hyperemia, and in both groups in MAI $(891.3 \pm 226.1$ versus $643.5 \pm 134.3 ; \mathrm{p}=0.001)$ and the time to reach it $(10.8 \pm 4.3$ versus $5.5 \pm 2.5 ; \mathrm{p}=0.001)$.

\section{Discussion}

Nailfold videocapillaroscopy is one of the best noninvasive imaging techniques to evaluate microcirculation in vivo and has been shown to be applicable to the study of many rheumatic diseases, specially in systemic sclerosis ${ }^{14}$. Patients with rheumatic diseases presented with morphological abnormalities, such as increase in the vascular loop diameter and tortuosity. This pattern was also observed in diseases such as dermatomyositis and presclerodermic Raynaud's phenomenon ${ }^{15}$. These patients had also decrease of blood flow speed ${ }^{14}$. More recently, this method has been used to evaluate microcirculation in extra-rheumatic diseases such as arterial hypertension, diabetes mellitus, Crohn's disease and psoriasis.

Table 1 - Projected area of transverse segment (TSA) before ischemia, maximum post-ischemia area and time to reach maximum post-ischemia area

\begin{tabular}{lccc}
\hline Groups & TSA $\left(\mu^{2}\right)$ & MAI $\left(\mu^{2}\right)$ & MAlt $(s)$ \\
& $\mathrm{p}=0.001$ & $\mathrm{p}=0.001$ & $\mathrm{p}=0.001$ \\
\hline \multirow{3}{*}{ TS } & Mean \pm SD & Mean \pm SD & Mean \pm SD \\
Control & $706.8 \pm 139.1$ & $891.3 \pm 226.1$ & $10.8 \pm 4.3$ \\
\hline
\end{tabular}

TSA: area of transverse segment before ischemia; MAI: maximum post ischemia area; MAlt: time to reach maximum post ischemia area; TS: Turner syndrome; SD: standard deviation.
Capillary nailfold flow responses to ischemia are well studied among diabetes through dynamic videocapillaroscopy (VC). Most studies in diabetic patients show reduced flow velocity and more time to get maximum velocity after induced ischemia than among controls. Other studies in diabetic individuals showed the same response to heat stimulus and nitrous acid intravenous infusion and after 3-minute arterial occlusion using laser Doppler anemometry ${ }^{16}$.

Lu et al. have reported advantages in the use of post occlusive reactive hyperemia (PRH) as a means of standardizing assessment of microcirculatory flow regulation ${ }^{17}$.

Tooke highlighted the role of endothelium as the main responsible for capillary flow regulations through its ability to release several mediators that promote vasodilatation in response to ischemia and vasoconstriction to restore capillary area after adequate oxygen offer ${ }^{18}$. He emphasized the role of endothelium to promote platelet adherence, aggregation and control of homeostasis. Those factors allied to blood viscosity are important to cause flow abnormalities among diabetic patients and even in insulin resistance syndrome ${ }^{19}$.

TS is associated to insulin resistance and the cardiovascular disease is the most prevalent cause of morbidity in these patients ${ }^{9}$. Coelho et al. showed morphological changes in patients with TS when compared to control group, specially tortuosity ${ }^{20}$.

There was not a study evaluating flow response to ischemia using capillary nailfold dynamic videocapillaroscopy among TS patients. Our study was compared to studies with diabetic patients.

Videocapillarocopy is unable to show capillary wall, but the erythrocyte images reflect wall thickness because its diameter is higher than capillary diameter and it has to be deformed to flow inside it. Meyer, Pfohl and Schatz showed positive correlation between capillary apex diameter and flow velocity among diabetic patients ${ }^{21}$.

The maximum post ischemia area was increased in TS when they were compared to control. Halfoun el al. studied diabetic patients using videocapillaroscopy and their results were similar. They found no differences in basal areas of transverse segments, but there was a significant increment between basal and maximum area among diabetic patients when compared to control group ${ }^{22}$.

Chang et al. studied microcirculation in patients with diabetes mellitus using dynamic capillaroscopy and evaluated peak blood cell velocity ( $\mathrm{pCBV}$ ) after post occlusive reactive hyperemia response and found that $\mathrm{pCBV}$ was slowed down in diabetic patients with or without retinopathy when compared with controls ${ }^{23}$.This functional parameter 
shows more sensitivity and detects changes earlier than morphologic abnormalities; this response is independent of neural mechanisms and the deviation of normal response curve in diabetic patients may be due to impaired myogenic mechanism ${ }^{23}$.

The time to reach MAI was different among TS and controls in our study. Halfoun et al. found that MAIt was significantly increased among diabetic individuals when compared to healthy control patients ${ }^{22}$. This impairment of cutaneous microcirculation in TS with a 1-minute digital arterial occlusion may be compared with the slow blood cell velocity found by Chang et al. in diabetic patients. This difference in MAIt is very important because studies of microcirculation consider that the time-to-peak velocity after a 1-minute occlusion of the flow to one of the fingers is the most stable variable during $\mathrm{PRH}^{23-25}$.

The prolonged maximum vasodilatation in response to ischemia among TS patients suggests abnormal adaptation to hypoxia event and this fact is concordant with studies that show the same characteristics in diabetes mellitus and a reduced increment of flow velocity during reperfusion.

We conclude that patients with TS showed changes of capillary response to ischemia compared to control group through bi-dimensional measures of projected area of capillary loops transverse segment in videocapillaroscopy. There were differences among TS and control in maximum area increments and time to reach, suggesting abnormalities in reperfusion and capillary flow, but there are few recent studies to be compared with our results and this is a limitation of our research.

We suggest that further studies studies that use other techniques to assess endothelium function in TS producing results comparable to ours.

\section{References}

1. Bondy, CA; Turner Syndrome Study Group. Care of girls and women with Turner Syndrome: a guidline of Turner Syndrome Study Group. J Clin Endocrinol Metab. 2007;92:10-25.

2. Stochholm K, Juul S, Juel K, Naeraa RW, Gravholt CH. Prevalence, incidence, diagnostic delay, and mortality in Turner Syndrome. J Clin Endocrinol Metab. 2006;91:3897-902.

3. Bondy CA. Turner syndrome 2008. Horm Res. 2009;71:52-6.

4. Dulac Y, Pienkowski C, Abadir S, Tauber M, Acar P. Cardiovascular abnormalities in Turner's syndrome: what prevention? Arch Cardiovasc Dis. 2008;101:485-90.

5. Gravholt $\mathrm{CH}$. Epidemiological, endocrine and metabolic features in Turner syndrome. Eur J Endocrinol. 2004;151:657-87.

6. Bakalov VK, Cooley MM, Quon MJ, et al. Impaired insulin secretion in the Turner metabolic syndrome. J Clin Endcrinol Metab. 2004;89:3516-20.
7. Alves STF, Gallichio CT, Guimarães MM. Insulin resistance and body composition in Turner syndrome: Effect of sequential change in the route of estrogen administration. Gynecol Endocrinol. 2006;22:590-4.

8. Gravholt $\mathrm{CH}$. Epidemiology of Turner syndrome. Lancet Oncol. 2008;9:193-5

9. Ho VB, Bakalov VK, Cooley M, et al. Major vascular anomalies in Turner Syndrome: prevalence and magnetic resonance angiographic features. Circulation. 2004;110:1694-700.

10. Bannink EM, van der Palen RL, Mulder PG, de Muinck KeizerSchrama SM. Long-term follow-up of $\mathrm{GH}$-treated girls with Turner syndrome: metabolic consequences. Horm Res. 2009; 71:343-9.

11. Tooke JE, Hannemann MM. Adverse endothelial function and the insulin resistance syndrome. J Intern Med. 2000;247:425-31.

12. Gravholt CH, Nyholm B, Saltin B, Schmitz O, Christiansen JS. Muscle fiber composition and capillary density in Turner syndrome: evidence of increased muscle fiber size related to insulin resistance. Diabetes Care. 2001;24:1668-73.

13. Halfoun VLRC, Fernandes TJ, Pires MLE, Braun E, Cardozo MGT, Bahbout GC. Estudos morfológicos e funcionais da microcirculação da pele no diabetes mellitus. Arq Bras Endocrinol Metab. 2003;47:271-9.

14. Gallucci F, Russo R, Buono R, Acampora R, Madrid E, Uomo G. Indications and results of videocapillaroscopy in clinical practice. Adv Med Sci. 2008;53:149-57.

15. Lambora SN, Müller-Ladner U. The specificity of capillaroscopic pattern in connective autoimunne diseases. A comparison with microvascular changes in diseases of social importance: arterial hypertension and diabetes mellitus. Mod Rheumatol. 2009;19:600-5.

16. Meyer MF, Rose CJ, Schartz H, Klein HH. Effects of a short-term improvement in glycaemic control on skin microvascular dysfunction in Type 1 and Type 2 diabetic patients. Diabet Med. 2009;26:880-6.

17. Lu Q, Freyschuss A, Jonsson AM, Björkhem I, Henriksson P. Postocclusive reactive hyperemia in single nutritive capillaries of the nail fold: methodological considerations. Scand J Clin Lab Invest. 2002;62:537-9.

18. Tooke JE. Endothelium: the main actor or choreographer in remodelling of the retinal microvasculature in diabetes? Diabetologia. 1996;39:745-6.

19. Golster H, Hyllienmark L, Ledin T, Ludvigsson J, Sjöberg F. Impaired microvascular function related to poor metabolic control in young patients with diabetes. Clin Physiol Funct Imaging. 2005;25:100-5.

20. Coelho SCS, Ramos AD, Pinheiro VS, et al. Nailfold video capillaroscopy in Turner syndrome: a descriptive study. I Vasc Bras. 2007;6:325-31.

21. Meyer MF, Pfohl M, Schatz $\mathrm{H}$. Assessment of diabetic alterations of microcirculation by means of capillaroscopy and laser-Doppler anemometry. Med Klin (Munich). 2001;96:71-7.

22. Halfoun VLRC, Pires MLE, Fernandes TJ, Victer F, Rodrigues KK, Tavares R. Videocapillaroscopy and Diabetes mellitus: area of transverse segment in nailfold capillar loops reflects vascular reactiviy. Diabetes Res Clin Pract. 2003;61:155-60. 
23. Chang $\mathrm{CH}$, Tsai RK, Wu WC, Kuo SL, Yu HS. Use of dynamic capillaroscopy for studying cutaneous microcirculation in patients with diabetes mellitus. Microvasc Res. 1997;53:121-7.

24. Tooke JE, Ostergren J, Lins PE, Fagrell B. Skin microvascular blood flow control in long duration diabetics with and without complication. Diabetes Res. 1987;5:189-92.

25. Fredriksson I, Larsson $M$, Nyströn $F H$, Länne $T$, Ostgren $C$, Strömberg T. Reduced arteriovenous shunting capacity after local heating and redistribution of baseline skin blood flow in type 2 diabetes assessed with velocity-resolved quantitative laser Doppler flowmetry. Diabetes. 2010;59:1578-84.

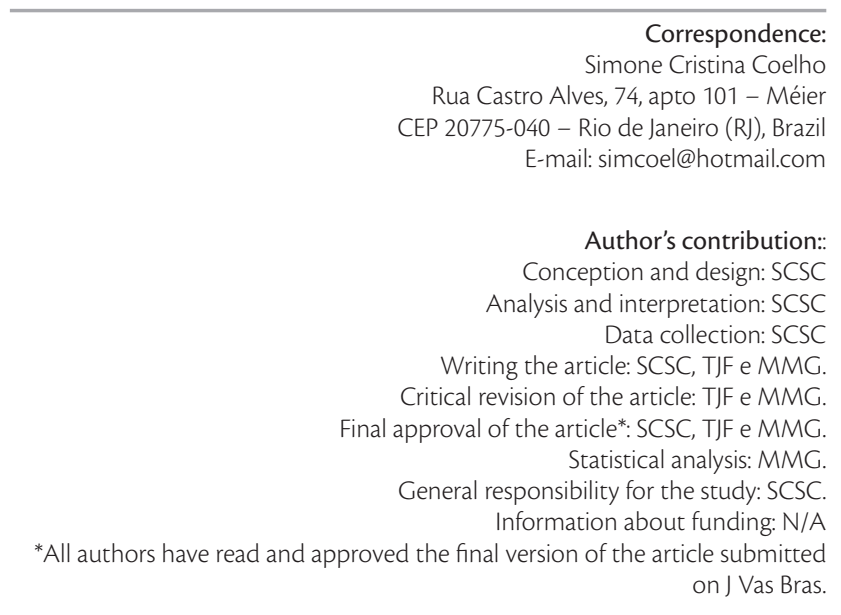

